\title{
Critical psychiatry in practice
}

\author{
Philip Thomas \& Patrick Bracken
}

\begin{abstract}
The ideas of critical psychiatry are influencing a growing number of psychiatrists in Britain and elsewhere. In this article we examine the origins and development of critical psychiatry over the past 25 years, through the work of philosophers such as Foucault and of critical social theorists such as Ingleby, Miller and Rose. We outline the important differences between critical psychiatry and antipsychiatry. Finally, we examine the current status of critical psychiatry, and what is called postpsychiatry. We regard both as an attempt by practising psychiatrists to engage with service users' concerns about psychiatry, with government policies that stress democracy, citizenship and the importance of social and cultural contexts in health care, and with what might broadly be described as postmodernism.
\end{abstract}

Across the world, the landscape of mental health care is changing rapidly. There are several reasons for, and dimensions to, these changes. At one end of the spectrum are shifts in government health policy. At the other is the emergence of the user movement. Over the past 5 years the British government has initiated a series of major health reforms to improve service quality through the investment of additional resources. These reforms, described in the National Health Service (NHS) Plan (Department of Health, 2000), represent a fundamental challenge to the old order of beneficent paternalism that has characterised professional work since the birth of the NHS. If implemented, these changes have profound implications for our work. First, there is an expression of democratic ideals: a serious concern with professional accountability and the right of patients as citizens (who fund the NHS through taxation) to be fully involved in all aspects of their care. It is worth noting that the word 'citizen' and its derivatives appears 19 times in the NHS Plan. Second, the NHS Plan attaches particular significance to the social, cultural and economic contexts of health care. Overcoming poverty, exclusion and discrimination, and working for the provision of decent housing and opportunities for employment, are presented as important aspects of health policy.

These policy changes resonate with the views of service users. The emergence of a wide variety of service user groups has been one of the most significant developments in mental health care in the past 15 years. Service user groups are heterogeneous. Some are happy to accept the idea that they suffer from illnesses such as schizophrenia or affective disorders; they accept the language of psychiatry. Others reject the notion of mental illness completely, and are incensed that they might be forced to take medication and have their liberty taken away because their distress is interpreted in terms of illness; these people reject the language of psychiatry. Other groups lie somewhere between these extremes. Despite their differences, they share a common belief in their right to interpret their experiences in their own way, and to receive help accordingly. This can be seen in the outcome of recent user-led research (Faulkner \& Layzell, 2000; Rose, 2001), much of which demonstrates that service users want to understand their experiences in terms of social and cultural contexts, and that many of them find biomedical interpretations limited - at best unhelpful, and at worst harmful.

Changing government policies and the rise of the user movement are not distinct events, however. They both reflect other developments: economic, cultural and political. The rise of consumerism, the increasing importance of the media and the advent of globalisation have had profound effects on our assumptions about the nature of knowledge, expertise and the role of professionals. These trends are part of that wider cultural phenomenon referred to as the postmodern condition (Box 1).

Most of us find this confusing. How are we to make sense of it? How are we to negotiate our way

Philip Thomas is a consultant psychiatrist with the Bradford Assertive Outreach Team and a senior research fellow at the Centre for Citizenship and Community Mental Health, School of Health Studies, University of Bradford (25 Trinity Road, Bradford BD7 0BH, UK. E-mail: p.thomas@bradford.ac.uk). His main area of clinical interest is critical social and cultural psychiatry. His academic interests include hermeneutics, phenomenology and narrative. Patrick Bracken is Clinical Director of the West Cork Mental Health Services, Ireland. His clinical and research interests include service innovation and a community development approach to mental health services, asylum seekers and refugees, and conceptual aspects of psychiatry. 


\section{Box 1 Modernism and postmodernism}

Modernism

'Modernism' specifically refers to an aesthetic movement exemplified by the novels of Joyce and Kafka, the paintings of Picasso and Braque, the buildings of Le Corbusier, and the music of Schoenberg, Webern and Boulez. The word is also used in a wider sense, that of the 'modern age', referring to a period in Western history starting with the French Revolution in the 18th century and culminating in the rise of global capitalism in the late 20th century. Finally, modernism is also identified with the ideas of Descartes, Kant, Newton and Darwin, and a belief in the progress and advancement of humankind through rationality and scientific thought. In this sense it is sometimes referred to as the 'modern spirit'.

Postmodernism Postmodernism is difficult to define and has a number of meanings. The word probably originated in aesthetics and literary criticism, such as the 1960s writing of Frank Kermode, but its meaning has since widened. For example, in the 1970s it came to refer to the use of pastiche, eclecticism and heterogeneity of styles in literature and music (Luciano Berio's composition Sinfonia is an excellent example). It is also used to imply a position counter to modernism (see above). Finally, it is increasingly used today in relation to globalisation, the new information era and the associated breakdown of linguistic, cultural and national identities.

Postmodern condition Jean-François Lyotard's influential book The Postmodern Condition: A Report on Knowledge, first published in 1979, described how so-called 'grand narratives', guarantors of truth such as Marxism, science and religion, have lost their legitimacy and authority (Lyotard, 1984). Lyotard questioned the Enlightenment assumption that science and rationality lead to progress and improvement.

Postmodern theory Postmodern theory carries a wide range of influences, including feminism (e.g. Gilligan, 1982) and philosophy (e.g. Heidegger, Foucault and Wittgenstein). Feminist writers such as Gilligan argue that so-called grand narratives, far from being impersonal and objective, contain deeply embedded assumptions that privilege the male perspective (she writes about psychological experiments comparing male and female moral development). The philosophies of Heidegger and Wittgenstein are aimed at some of the central assumptions about selfhood, the relationship between self and society, and body-mind dualism that lie at the heart of Western thought.

around the febrile, changing landscape in which we practise? In this article we try to provide a way of thinking about these issues that helps us to orient ourselves and points a way forward. This rests on the premise that the change and turmoil we face today reflect a basic feature of our work: the contested nature of madness.

Ultimately, critical psychiatry proposes that there should be limits to psychiatry. Setting such limits opens up a space for the voices of those who historically have been excluded from debates about mental health - the service users. This article is not a comprehensive review of critical psychiatry, but by examining two key texts, those by Ingleby (1981) and Miller \& Rose (1986), we hope to introduce the interested reader to a number of central issues. Our focus here is limited to some of the philosophical ideas behind critical psychiatry. We also recommend the article by our colleague Duncan Double, published in the BMJ (Double, 2002). Although there is insufficient space for us to consider the 'antipsychiatry' movement in detail, we highlight key differences between anti-psychiatry and critical psychiatry. This is important because many people confuse the two.

\section{The origins of critical psychiatry}

David Ingleby and his fellow contributors to Critical Psychiatry: The Politics of Mental Health (Ingleby, 1981) were united in the belief that, although the locus of care had shifted from institution to community, the fundamental problems of psychiatry remained. The underlying premise of Ingleby's ideas is that mental illness is a political 
issue. Although he refers to Foucault, his book was written before Foucault's ideas had made their full impact. Ingleby accepts the existence of states of profound suffering and alienation seen in psychosis, but questions the interpretations psychiatry makes of such states. He argues that we can best understand conflicting viewpoints about the nature of madness in terms of underlying philosophical systems, and that these systems of thought are ultimately driven by moral and political considerations. Thus, his analysis is conceptual rather than empirical. He argues that the understanding of madness has always been contested and that this reflects two fundamentally different approaches to human experience. Positivism applies the scientific methods of the natural sciences to human experience. Hermeneutics, on the other hand, regards the subject matter and methodology of the human sciences as one and the same thing. This debate about the human sciences dates back at least to the 19th century and the Methodenstreit (methodological controversy) within the humanities in Germany. For Ingleby, the problem of psychiatry is the problem of the application of positivism to human experience. How does he see these problems?

\section{Positivism and psychiatry}

First, Ingleby questions the idea that positivist psychiatry is objective, neutral and value-free. Here, Ingleby is influenced by the ideas of Thomas Kuhn (1962) and the Frankfurt school of philosophy, especially Jurgen Habermas (1972) - see Box 3. He asks whose interests psychiatry serves and whether we want the type of society towards which it leads us. Positivism in psychiatry makes two assumptions: that observations can be made objectively (that they can be defined, that they are valid and can be applied reliably) and that theories in psychiatry can be constructed using causal determinism (Box 2), as in the natural sciences. He argues that the notion of objectivity in psychiatry is a myth. This is because it is not possible for us to talk about our inner psychological worlds in the same way that we talk about the natural world. In this belief Ingleby owes

\section{Box 2 Causal determinism}

The philosophical notion that everything that happens is determined by preceding events. It implies that if we have a full description of a physical system at one point in time, we can predict with certainty what its state will be at subsequent points in time, as can be seen in Newton's model of the universe. something to the later philosophy of Wittgenstein (1967) and the hermeneutic phenomenology of Heidegger (1962) and Merleau-Ponty (1962). Consider anger. Most of us have no difficulty in identifying anger; it is the very nature of human experience, grounded in our common sense of what it is to be human, to be able to identify the emotion and the human contexts in which it occurs. In other words, we rely on a taken-for-granted, interpretive competence to recognise anger. The difficulty is that such a common-sense approach does not meet positivism's need for explicit criteria, so science relies on ad hoc definitions that obscure the tacit assumptions necessary for applying them in a given situation. Descriptions of most psychiatric phenomena, such as hearing voices or blunted affect, are of this nature. An alternative approach, adopted by ultra-positivists such as Eysenck, substitutes these problematic phenomena with test scores or physiological measures such as skin conductance. This is circular, because these measures can only be validated against psychiatrists' subjective judgements. Ingleby argues that decisions as to whether someone is depressed, psychotic or hearing voices are rooted in our common-sense understandings of madness. To claim, as positivism does, that such decisions could be grounded in something that transcends common sense - that is to say, in neutral, value-free science - simply does not make sense.

\section{The censorship of theories}

Ingleby's second set of arguments concerns what he calls the censorship of theories, and particularly the claim made by science that the only legitimate forms of explanation are causal. This exists in a 'strong' form (the disease model), which maintains that psychosis is caused by disturbances in neurophysiological or neurochemical function. A weaker variant is found in 'eclectic' psychiatric practice, which maintains that, although social and psychological factors might be important, to be taken seriously they have to be stripped from background context and regarded as 'independent variables'. Positivism is simply unable to deal with the complexity of social and cultural environments. In reality, these worlds are rich in meaning and resist linear causal models. The essential point is that contexts provide grounds or reasons for human action, not causes of it. This means that understanding and interpretation should be central to our approach to psychosis.

Again, the influence of Wittgenstein emerges. In Philosophical Investigations, Wittgenstein (1967) argues that the 'laws' underlying human agency are simply not of the same logical type as those that 


\section{Box 3 Key figures in critical thought}

Michel Foucault (1926-1984)

One of the most influential philosophers of the 20th century, Michel Foucault in his early work Madness and Civilization examined the origins ('archaeology') of psychiatry, seeing it as an act of social exclusion that resulted in the incarceration of the insane. His later work on the nature of power (e.g. The History of Sexuality) considers the central role of power in the creation of human subjectivity, i.e. in setting out what it is possible, or not possible, to think.

\section{Jurgen Habermas (1929-)}

A member of the Frankfurt school of philosophy, his early work Knowledge and Human Interests was much influenced by Kantian and Marxist philosophy, in trying to understand the origins of social science in terms of their historical and cultural contingencies. The increasing specialisation of knowledge has led to a situation in which there is little critical dialogue between academic disciplines, resulting in a naïve positivism. It is this that Ingleby attacks.

\section{Martin Heidegger (1889-1976)}

Heidegger's work was very much an attempt to go beyond the thinking of Descartes and other philosophers of the Enlightenment, and he stands as one of the most important inspirations for European philosophy in the second half of the 20th century. His work is the central reference point for existentialism, hermeneutics and postmodern thought. Yet he remains a controversial figure owing to his membership of the Nazi party in the 1930s. In his magnum opus Being and Time, he raises the question of 'being'. In Heidegger's work this is the question of how the world makes sense for us, of how it is meaningful.

Maurice Merleau-Ponty (1907-1961)

A French phenomenologist greatly influenced by Heidegger, Merleau-Ponty was a founder (with Sartre) of existentialism. His great work is the Phenomenology of Perception, in which he develops the idea of the body as an ambiguous mode of existence, situated between psychology and

govern the physical or natural world. Unlike the laws of nature, they are made by humans and relate only to human agency. For this reason, Ingleby argues that positivism writes human agency out of the frame. In psychiatry, which deals with such issues as individual struggles with meaning, emotion and social position, this neglect of agency imposes severe constraints. biology. Having a body is to exist in a particular culture for a particular time and to identify and commit oneself to particular projects. Our bodies define our spatiality and draw us into the physical world. Our bodies also define our temporality, especially our finitude. The body is the locus of past, present and future. Thus, embodiment becomes an attempt to surmount the limitations of Cartesian (body/mind) dualism.

Lev Vygotsky (1896-1934)

Lev Vygotsky was a Russian developmental and educational psychologist, whose project was a 'Marxist' psychology. His empirical studies of child language acquisition stressed the primacy of social and cultural processes through interactions with caregivers. His work may be seen in some ways as an empirical validation of Wittgenstein's later philosophy. Vygotsky's work, alongside that of Wittgenstein, has become enormously influential in the past 25 years, particularly in 'discursive' psychology. It, too, poses a challenge to cognitivist conceptions of mind, and stresses the interrelatedness of mind, society and culture.

Ludwig Wittgenstein (1889-1951)

Ludwig Wittgenstein was one of the major influences on 20th century philosophy. His early classic, Tractatus Logico-Philosophicus, was written while he was serving as a medical orderly in the First World War. The Tractatus sets out a representational view of language in which the structure of propositions may be seen as representing states of affairs as they exist in the world. In his later Philosophical Investigations, Wittgenstein reverses this view of language, and he rejects the view that the meaning of a word is the thing it stands for. Instead, he proposes that the meaning of a word is to be found in the use to which we put it. This has profound implications for our understanding of mind and language (stressing the social and cultural rather than the cognitive), and the limitations of language in talking about our inner worlds.

\section{Interpretive psychiatry}

Ingleby proposes an interpretive (hermeneutic) psychiatry as an alternative to positivism. Hermeneutics takes for granted that human beings engage in meaningful behaviour that transcends causal explanation and objectivity. If we relinquish positivism, the distinctions between observer and 
subject, or between describing and explaining, become blurred, and combine in the act of interpretation.

Interpretation has an extensive heritage in philosophy, and its influence can be found particularly in the phenomenology of Heidegger and Merleau-Ponty, all of which is rooted in commonsense ideas of what we believe being human is all about. Csordas (1994) provides an excellent example of such a hermeneutic-phenomenological account, which resists the temptation to move from biological to cultural determinism. A non-philosophical alternative can be found in the work of Oliver Sacks (1986), who describes beautifully the inadequacy of biological or psychological accounts of neurological disorders alone in accounting for the complex experiences that occur in these conditions. Sacks points out that we have to place the biological and psychological within the context of a person's narrative or life history.

Ingleby moves away from Heidegger and Merleau-Ponty and looks to a revised form of psychoanalysis to ground a more adequate (in his view) understanding of distress. Superficially, some aspects of Ingleby's ideas resonate with antipsychiatry. Laing also attached a great deal of importance to understanding psychosis through a revised psychoanalysis. Like Szasz, Ingleby argues that positivism is well suited to psychiatry's role of social control, because it presents matters that are essentially cultural judgements about the nature of health or illness, as empirical facts, but he differs from Szasz over questions of the welfare of the individual. For Szasz, whose moral ideal is that of personal freedom, the problem of psychiatry is that it places the common good, or the values of social institutions (the family, the state, work), above those of the individual. Ingleby argues that social institutions do not necessarily represent the common good. Rather, they represent a group of interests hiding under the banner of economic progress. Here he is influenced by the early writings of Foucault (1967), who described the exclusion of the insane as an act of incarceration achieved through the use of high walls, barred doors, chains and padlocks. Ingleby argues that the medical ideology of psychiatry achieves the same objective of social control without physical restraints.

\section{Who defines abnormality?}

Although psychiatry became influential in setting the experiences of psychiatric patients outside the boundaries of ordinary meaningful human experience, Ingleby fails to account for the extraordinary influence of psychiatry and psychology in defining what is 'normal' or 'abnormal', or - to put it another way - in specifying which ways of experiencing the world (or subjectivities) are acceptable and which are not. In addition, one is left feeling that Ingleby maintains a strong belief in the ability of the Enlightenment ideals of rationality and progress (through the philosophy of Marx and the influence of psychoanalysis) to solve the riddle of madness. This is where he differs from Miller and Rose.

\section{The Power of Psychiatry}

The Power of Psychiatry (Miller \& Rose, 1986) was published only 5 years after Ingleby's work, yet the influence of Foucault's later writings is clear. Marx and Freud are no longer the inspirations for a critical approach to psychiatry; they have become part of the problem. The book offers an examination of the origins and social functions of British psychiatry over the previous 100 years. Like Ingleby, Miller and Rose take issue with the epistemological (Box 3) premise of anti-psychiatry - that psychiatric illness does not exist - because it denies the suffering of those who experience emotional distress. In addition, they believe that anti-psychiatry is incapable of illuminating the social and political functions of psychiatry. For this reason, they argue that it is more helpful to accept the reality of psychiatry (as a social practice) rather than engage in empty arguments about the existence or not of mental illness.

Miller (1986) points out that anti-psychiatry evolved in a culture preoccupied with personal autonomy and subjectivity, that of the 1960s. The analysis of the power of psychiatry mounted by the anti-psychiatrists is simplistic, because it crudely equates power with the suppression of subjectivity. It says nothing of power and the creation of subjectivity. This idea, taken from Foucault, lies at the heart of Miller \& Rose's critique of psychiatry. The power of psychiatry is to be found in the possibilities it creates for us, especially in terms of regulating our behaviour. Such an analysis is necessary because psychiatry operates far beyond the walls of the institution. Today, psychiatry serves as a technology that helps to constitute a radically different set of power relationships in advanced liberal democracies. Mental health confers economic

\section{Box 3 Epistemology}

Epistemology pertains to knowledge and belief. It is concerned with asking questions about the nature of knowledge, and how it is possible to believe what we believe. 
advantage, is seen as a social necessity, and has become an object of personal desire. Psychiatry is found in every corner of our cultural lives. Psychiatrists and psychologist pontificate upon the great events and tragedies of our time. They are called in to interpret and prognosticate in our newspapers, television, radio and magazines. More so than any other branch of medicine, psychiatry has become constitutive of cultural life itself. How are we to understand this?

Miller and Rose see psychiatry as a form of government of the self, in that it makes it possible for us to talk about ourselves, our feelings and our lives, in particular ways. This is what is meant when we speak of psychiatry creating subjectivities. The power of psychiatry is not simply to be found in coercion; it is also to be found in the possibilities it creates for us. For example, in Western societies our experiences of sadness and unhappiness can be talked about within the broad classification of 'depression'. The experience of hearing voices, on the other hand, is attributed to the 'narrow' diagnosis of schizophrenia, which effectively closes down other ways of accounting for the phenomenon (see Leudar \& Thomas (2000), particularly Chapters 6 and 7, for a detailed account of this). Thus, there are negative and positive aspects of power in psychiatry. It is not simply a tool for the repression of individual subjectivity; it also generates subjectivities. In other words, it both opens up and closes down possibilities for all of us to understand ourselves.

\section{Technologies of the self}

In The History of Sexuality, Foucault (1981) developed the concept of 'technologies of the self', arguing that discipline operates most effectively through processes of self-regulation of the person. This implies that we all possess the ability for selfreflection and introspection, and that psychiatry and psychology define this ability. Thus, psychiatry patrols the boundaries between reason and unreason, between sanity and madness. Foucault argued that unreason, or madness, have become constituted as Other, knowable only through the language of reason. Thus we have a monologue of reason about unreason, which excludes the voices of the insane. This, Foucauldian analysis is vitally important in understanding why many service users are disaffected with psychiatry. It also points the way forward.

\section{The influence of government}

Rose (1986) examines in detail the social and political circumstances in which British psychiatry became so influential (i.e. the genealogy of psychiatry: see Box 4). Although his argument is developed in relation to a British context, it is arguable that it is internationally relevant, at least to most Western nations.

At the start of the 20th century, when it was at the height of its success in establishing the causes of diseases, medicine became involved in a new social concern: environmental health. The First World War drew attention to the poor state of health of workingclass soldiers, many of whom were rejected for military service. There was a growing awareness that disease and health were not simply matters affecting individuals, but were closely related to the living conditions of the population as a whole. As a result, government power extended to the political regulation of the habits of the population through the management of domestic life, in the interests of health and well-being. This had implications for psychiatry. In the UK, the Royal Commission on Lunacy and Mental Disorder of 1926 declared that:

'The problem of insanity is essentially a public health problem to be dealt with on modern public health lines' (quoted by Rose, 1986: p. 50).

Psychiatry also cast its gaze on antisocial and immoral behaviours, providing medical explanations for them. It came to be seen as an authority on all aspects of the human situation, including family structure and child-rearing practices. It advocated eugenic campaigns to control the 'morally insane', criminals and the 'mentally defective', through compulsory sterilisation. Increasingly, the ideal of mental health became a personal responsibility and a national objective for government. According to Rose, these processes changed the nature of madness as a social phenomenon. Mental illness was no longer limited to psychosis as a fundamental otherness that challenged the moral order, but expanded to include personal unhappiness and social inefficiency. This happened partly through the role of psychiatry and psychology during the Second World War in the management of the human factor in social life.

Thus, the Second World War opened up a new domain of social reality for psychiatry, which assumed the task of dealing with those suffering from neuroses that impaired their productivity and employability. This, together with the foundation of the NHS and the welfare state, established a new context for psychiatry, which was legitimised by social policy such as the Mental Health Act 1959. Although this granted doctors specific powers in respect of involuntary admission and compulsory treatment, Rose argues that it would be wrong to interpret this as an extension of the medicalisation of social control. This is because the strategy sought to minimise the role of incarceration by improving 


\section{Box 4 Key ideas in critical thought}

\section{Critical theory}

Critical theory refers specifically to the approach to the study of society developed in the mid-20th century, associated with the Frankfurt school of philosophy (Max Horkheimer, Theodor Adorno, Herbert Marcuse and latterly Jurgen Habermas). It started as a reaction against totalitarianism in Europe, and the threat to individual autonomy. In recent years critical theory has addressed the social role of science, and especially the nature of theory in human sciences. This has resulted in the growth of critical psychology since the late 1980s, and more recently of critical psychiatry.

\section{Genealogy}

Genealogy is a term that has risen to prominence following the work of Foucault, although it was first used by Nietzsche. Genealogy is a method of historical critique, the purpose of which is to challenge established norms and ways of seeing the world. Foucault achieved this through historico-sociological analyses, and this can be clearly seen in the work of Miller and Rose.

\section{Hermeneutics}

Hermeneutics (from Hermes, the Greek messenger of the gods) refers to the art of interpretation. Originally used to describe theologians' attempts to understand the meaning of biblical texts, it was extended by the 19th-century philosopher Dilthey to apply to all human behaviour and experience. In Being and Time, Heidegger (who studied with Dilthey) developed a hermeneutic phenomenology concerned with the interpretation and meaning of being itself.

\section{Positivism}

This concept is associated with the work of the French sociologist Auguste Comte, who in the mid19th century proposed that human thought has evolved through a series of stages: religious, metaphysical and scientific. Positivism stressed

the links between medical and social care agencies, making it easier for people to move between them.

Rose (1986) argues that by positing a simple dichotomy between the (bad) medical model and (good) psychotherapies, anti-psychiatry obscured the problematic features of both. After the Second World War there was a growth in physical and pharmacological treatments, social therapies, psychoanalysis and behaviour therapy. These 'therapies of normality' were aimed not at curing intellectual or emotional deficits, but at moulding the unity of natural and human sciences, with the implication that human beings are suitable subjects for the formal methods of scientific inquiry. This position is rejected by critical theorists of the Frankfurt school.

\section{Reification}

Originally, reification was a concept used by Marx to refer to the way in which social relationships are seen to be no different from the relationships between things. For Marx, reification was an outcome of alienation, the division between workers and the product of their work. Ingleby applies the term in a way more in keeping with the New Left and the Frankfurt school, to the treatment of human beings as things, as objects for manipulation through (for example) the processes of causal determinism.

\section{Subjectivity}

Since the European Enlightenment and the work of Descartes, the idea of subjectivity has been principally defined (even privileged) with reference to the perspective of the first-person (masculine) standpoint. The ontological essence of being human is thus the individual's consciousness. Twentieth-century continental philosophy rejects this viewpoint. Foucault, for example, maintains that subjectivity is constructed through language, politics and culture.

\section{Technologies of the self}

This an idea that emerged in Foucault's writing from the late 1970s onwards, technologies of self include a wide variety of practices (such as psychiatry) or 'techniques' (such as therapy) that may be used to change the self. They are historically situated within power relationships. For Foucault, this concept can be traced back to classical Greece, but writers influenced by Foucault, such as Rose (1979), use the idea in connection with psychiatry and psychology - the so-called 'psy' complex.

subjectivity in desired directions. The point here is that these new 'technologies of the self' (Box 4) transformed the difficulties of everyday living into psychological problems:

'they become not intractable features of desire and frustration, but malfunctions of the psychological apparatuses that are remediable through the operation of particular techniques' (Rose, 1986: p. 81).

Technologies of the self make it possible to transform a long-term personal relationship such 
as marriage from an ethical obligation to a matter of personal fulfilment, or allow us to free ourselves from the dread we experience at the thought of our mortality. Death itself becomes a manageable psychological problem.

\section{Critical psychiatry today}

So far we have limited ourselves to an analysis of two important works in the tradition, both of which were written by non-psychiatrists. What marks out critical psychiatry today is that many of its advocates are practising psychiatrists. A growing number of psychiatrists are now engaging openly with these ideas. Critical psychiatry may be understood as an alliance around the following themes.

- Psychiatry is based on a set of assumptions about the nature of mind, meaning and knowledge and the relationships between psychology and sociocultural realities. These assumptions can be questioned. They do not represent a universal truth.

- Service users and governments are asking psychiatry to move beyond the narrow and sometimes simplistic frameworks that guided the discipline in the 20th century. This should not be construed as a threat but rather as an opportunity to reconfigure the relationship between medicine and those who suffer.

- There is a need for psychiatrists to develop more flexible ways of engaging with states of madness and distress. This means paying more attention to the different ways in which service users understand their experiences. The paper by Roberts \& Wolfson (2004), which engages positively with the emerging user-led concept of recovery, is an excellent example of this.

- Critical psychiatry is involved in campaigns to limit the control of psychiatry by corporations, most notably those of the pharmaceutical industry. It is also involved in campaigns to reduce the coercive side of psychiatric practice.

\section{Postpsychiatry}

Elsewhere, we have argued that the advent of the 'postmodern condition' and the emergence of postmodern philosophy have opened up new ways of thinking about mental health practice (Bracken \& Thomas, 2001). Some service users have asked for a move to 'postpsychiatry' (Campbell, 1996), and we have used this term as an organising principle for our own work. Postpsychiatry is not yet another model to compete with the 'medical' and 'social' models of psychiatry; instead, it points to the possibility (and the growing reality) of a new direction for mental health work, which moves beyond the theories of the 20th century. This move originates in our conceptual critique of psychiatry (Bracken \& Thomas, 2001), and in the work of service user groups such as Survivors Speak Out, the National Self-Harm Network, the Hearing Voices Network, Mad Pride and Mad Women, all of which reject medical accounts of their experiences and look elsewhere for their explanatory models. They also highlight the potential for harm caused by psychiatry.

Postpsychiatry seeks to understand why psychiatry is in this position, and to use this understanding to find theoretical and practical ways forward. While remaining part of the broad church of critical psychiatry, postpsychiatry makes the central claim that many of the problems of psychiatry arise from its identity as an enterprise of modernity. The Enlightenment focus on the individual self and the value of reason charted the course followed by psychiatry for 200 years, with the assumption that all its efforts were transparently for the good. Postpsychiatry holds that our discipline is blind to the limitations of its theoretical frameworks, and has overlooked the pain and suffering it can cause.

This has practical and theoretical dimensions if we are to move forward. On a practical level, we try to work with service users and carers to find new ways of doing mental health work. This happens at macro- and micro-levels. At the macro-level we are attempting to set up statutory services that genuinely involve collaboration between service user and carer groups, communities (especially Black and minority ethnic communities) and the professionals who serve them. We also support the emergence of selfdefined support groups in the voluntary sector. At the micro-level our work on trauma (Bracken, 2002), and on hermeneutics and psychosis, especially hearing voices (Davies et al, 1999; Thomas et al, 2004), stresses the inherently meaningful nature of these experiences within the context of the person's life history and circumstances. In a limited way, postpsychiatry is trying to chart a new relationship between medicine and the experiential world of madness, alienation and distress.

On a theoretical level, postpsychiatry has a number of key influences, but one of our most important goals is to take seriouslythe challenge posed by Foucault's critique. In the past, psychiatrists (particularly in Britain) have dismissed his position as 'anti-psychiatry'. We disagree. Few psychiatrists are aware of the true depths of Foucault's critique. Most have chosen to listen to those historians who articulate a 'progressivist' reading of the history of psychiatry. They argue that, because Foucault made some historical errors, 
his work can be dismissed. It is worth noting that Gordon has mounted a powerful defence of Foucault's history (Gordon, 1990). For postpsychiatry the most important feature of Foucault's work concerns the question of ethics. He presents ethics as a sensibility to Otherness, not as a system of rules or codes to be followed slavishly. He shows us how the generation of knowledge is not ethically neutral but at every step involves implications for other people. This view resonates strongly with feminist writing about ethics, particularly the work of Carol Gilligan (1982), who contrasts the dominant paradigmatic approach to ethics with feminist, or situated, ethics. Nowhere is this more apparent than in our work as psychiatrists, where we like to believe that our interventions are technical and value-free. Foucault helps us to move beyond this position and thus opens up a space in which we can see some of the harm caused by our interventions.

\section{Conclusions}

Critical psychiatry is starting to have an impact on mainstream psychiatry. The fact that $A P T$ is prepared to publish our article confirms this. Nevertheless, there is a great deal still to be achieved. Critical reflection on the history and the social position of our discipline are a central concern for critical psychiatry, and this way of approaching our discipline must be brought into the mainstream. It is no longer a marginal activity, and an exposure to 'critical thinking' is an important training issue. The greatest challenge for the future is to enable critical psychiatry and postpsychiatry to influence the training of psychiatrists.

\section{References}

Bracken, P. (2002) Trauma: Culture, Meaning and Philosophy. London: Whurr.

Bracken, P. \& Thomas, P. (2001) Postpsychiatry: a new direction for mental health. BMJ, 322, 724-727.

Campbell, P. (1996) Challenging loss of power. In Speaking Our Minds: An Anthology (eds J. Read \& J. Reynolds), pp. 56-62. London: Macmillan/Open University.

Csordas, T. (1994) Words from the Holy People: a case study in cultural phenomenology. In Embodiment and Experience: The Existential Ground of Culture and Self (Ed. T. Csordas), pp. 269-290. Cambridge: Cambridge University Press.

Davies, P., Thomas, P. \& Leudar, I. (1999) Dialogical engagement and verbal hallucinations: a single case study. British Journal of Medical Psychology, 72, 179-187.

Department of Health (2000) The NHS Plan: A Plan for Investment, A Plan for Reform. Cm 4818-I. London: HMSO.

Double, D. (2002) The limits of psychiatry. BMJ, 324, 900904.

Faulkner, A. \& Layzell, S. (2000) Strategies for Living: A Report of User-led Research into People's Strategies for Living with Mental Distress. London: Mental Health Foundation.

Foucault, M. (1967) Madness and Civilization: A History of Insanity in the Age of Reason (trans. R. Howard). London: Tavistock.
Foucault, M. (1981) The History of Sexuality (trans. R. Hurley). Harmondsworth: Penguin.

Gilligan, C. (1982) In A Different Voice: Psychological Theory and Women's Development. Cambridge, MA: Harvard University Press.

Gordon, C. (1990) Histoire de la Folie: an unknown book by Michel Foucault. History of the Human Sciences, 3, 3-26.

Habermas, J. (1972) Knowledge and Human Interests (trans. J. Shapiro). London: Heinemann.

Heidegger, M. (1962) Being and Time (trans. J. Macquarrie \& E. Robinson). Oxford: Blackwell.

Ingleby, D. (1981) Understanding 'mental illness'. In The Politics of Mental Health (ed. D. Ingleby), pp. 23-71. Harmondsworth: Penguin.

Kuhn, T. (1962) The Structure of Scientific Revolutions. Chicago: University of Chicago Press.

Leudar, I. \& Thomas, P. (2000) Voices of Reason, Voices of Insanity: Studies of Verbal Hallucinations. London: BrunnerRoutledge.

Lyotard, J.-F. (1984) The Postmodern Condition: A Report on Knowledge. Manchester: Manchester University Press.

Merleau-Ponty, M. (1962) Phenomenology of Perception (trans. C. Smith). London: Routledge \& Kegan Paul.

Miller, P. (1986) Critiques of psychiatry and critical sociologies of madness. In The Power of Psychiatry (eds P. Miller \& N. Rose), pp. 12-42. Cambridge: Polity Press.

Miller, P. \& Rose, N. (eds) (1986) The Power of Psychiatry. Cambridge: Polity Press.

Roberts, G. \& Wolfson, P. (2004) The rediscovery of recovery: open to all. Advances in Psychiatric Treatment, 10, 37-48.

Rose, N. (1979) The psychological complex: mental measurement and social administration. Ideology and Consciousness, 4, 5-68.

Rose, N. (1986) Psychiatry: the discipline of mental health. In The Power of Psychiatry (eds P. Miller \& N. Rose), pp. 43-84. Cambridge: Polity Press.

Rose, D. (2001) Users' Voices: The Perspectives of Mental Health Service Users on Community and Hospital Care. London: Sainsbury Centre for Mental Health.

Sacks, O. (1986) The Man Who Mistook His Wife for a Hat. London: Picador.

Thomas, P., Bracken, P. \& Leudar, I. (2004) Hearing voices: a phenomenological-hermeneutic approach. Cognitive Neuropsychiatry, 9, 13-23.

Wittgenstein, L. (1967) Philosophical Investigations (3rd edn) (trans. G. E. M. Anscombe). Oxford: Blackwell.

\section{MCQs}

1 Positivism:

a deals with the role of meaning and values in understanding human experience

$b$ provides a framework for the objective study of human behaviour

c is the main focus of Ingleby's critique of psychiatry

$\mathrm{d}$ originated in the work of Ludwig Wittgenstein

$\mathrm{e}$ is one of the philosophical ideas espoused by the Frankfurt school of philosophy.

\section{The work of Michel Foucault:}

a proposes that psychiatry originated through the social exclusion of the insane

b uses psychoanalysis as a hermeneutic framework

c was one of the main influences on the anti-psychiatry movement

d proposes that technologies of the self have a central role in social order and discipline

e has been used to argue that the power of psychiatry also involves the creation of subjectivity. 
3 Anti-psychiatry in the 1960s:

a gave rise to the critical psychiatry movement

b was largely influenced by psychoanalysis

c argued that the coercive powers of psychiatry are used to suppress individual freedom

$\mathrm{d}$ helped to clarify the problematic aspects of both psychiatry and psychoanalysis

e rejected Foucault's genealogical approach to understanding power.

4 The service user movement in Britain:

a has had a significant impact on the critical psychiatry movement

$\mathrm{b}$ is intent on purging mental health practice of the medical model

$c$ is challenging the epistemological basis of mental health practice through user-led research d provides, through the work of groups such as the Hearing Voices Network, opportunities for the exploration of alternative subjectivities

$\mathrm{e}$ is one of the main influences on postpsychiatry.

5 The philosophies of Heidegger and MerleauPonty:

a stress the importance of understanding the meaning of human experience within social, historical and cultural contexts

b stand firmly within the tradition of the Enlightenment philosophy of Descartes

c demonstrate the limitations of body/mind dualism in understanding human experience

d assume a representational view of language

e emphasise the value of the hermeneutic tradition in philosophy.

\section{Clinical Evidence Mental Health (third edition)}

Royal College of Psychiatrists/BMJ Publishing Group

This book contains the mental health section extracted from Clinical Evidence, Issue 11 (BMJ Publishing Group), the international source of the best available evidence for effective health care. The book presents clear, concise summaries of the current state of the evidence on the prevention and treatment of mental health disorders derived, where possible, from randomised controlled trials and systematic reviews.

This third edition covers 15 different mental health disorders, 27 questions, and over 200 interventions.

- Based on the latest Clinical Evidence search and appraisal results.

- Includes evidence on the short- and long-term treatment of mental health disorders and their complications.

- Assesses drug treatments, non-drug treatments and psychological therapies.

- Uses explicit methodology for selecting which evidence to summarise.

- Categorises interventions according to whether they have been found to be effective or not.

- Presents key messages and structured summaries of filtered evidence.

- Presents the balance between benefits and harms of intervention.

August 2004, Paperback, 210pp, ISBN 190467116 0, Price $£ 14.00$

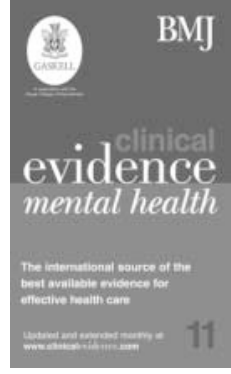

\section{NOW AVAILABLE FROM: Book Sales, Royal College of Psychiatrists,}

17 Belgrave Square, London, SW1X 8PG, United Kingdom.

Tel: +44 (0)20 72352351 Ext 146. Fax: +44 (0)207245 1231

Website: www.rcpsych.ac.uk/publications 